\title{
A Research Critique on the Lived-In Experience of Adolescents at Selected Orphanages in Thiruvallur District
}

\author{
Mrs. S. Tamil Selvi, Community Health Nursing, Dept., \\ M.Sc (N), (Ph.d) Lecturer, Saveetha College of Nursing, Saveetha University, Thandalam.
}

\begin{abstract}
Parents are the primary care givers of the children. Once a child loses a parent or both the parents, such children may be adopted by relatives from either of the parents' families. In most cases adopting parents live in a different environment to which a adolescent may not be familiar. These child when grows into adolescent associated with many physical and psychological problems. The present study was undertaken to critique the lived in experience of Orphan adolescents are vulnerable for a number of reasons. The study reveals that the efforts to improve their conditions in orphanages are important, the greater effort has moved to find stable homes for adolescent in such situations, where they may have the chance to experience the love of family despite their tragic past.
\end{abstract}

Key words; lived in experience, adolescents, orphanages.

Objectives

1. Elicit the lived-in experiences of adolescent in selected orphanages.

2. Explore the problem revealed by the adolescents.

\section{Introduction.}

World Orphanage Statistics, (2007) states that in Asia out of 993 million children 65 million children are orphans, 34 million are orphans in Sub-Saharan Africa out of 288 million children and out of 162 million adolescent, 8 million adolescent are orphan in Latin America and the Caribbean Children on the Brink, (2002) AIDS caused orphans will rise to nearly $50 \%$ by 2010 when it is

stigmated that the total number of orphans in the region will be 42 million. In Ukraine and Russia $10 \%$ $-15 \%$ of the adolescent who age out of an orphanage commit suicide before age of $18.60 \%$ of the girls are lured into prostitution. $70 \%$ of the boys become hardened criminals and many of these adolescent accept job offers that ultimately result in their being sold as slaves. Millions of girls are sex slaves today, simply because they were unfortunate enough to grow up as orphans. Reliable statistics are difficult to find, even the sources often lists only the estimates, and the street adolescent are rarely included. But even if these figures are exaggerated by double, it is still an unacceptable tragedy that over a million adolescent would still become orphans every year, and every year 7 million adolescent would still grow to adulthood as orphans with no one to care for and no place to live in. They are totally vulnerable and easily fall as a prey to the predators and the slave recruitersThe Government of India, (2000) stated that adolescent who are living in Orphanages in North West, Delhi, tends to be in inadequate facilities and unhygienic environment. The boys were malnourished and the promotion activities are needed to improve the health status of this population.

AMES. T, (2000) examined the behavioral problems of institutionalized adolescent. The majority of orphanage adolescent (84\%) displayed stereotyped behavior, mostly in the form of rocking. These studies have found that orphanage adolescent display rather unique behavioral problems when compared with the home reared adolescent of the country.

\section{Review of Literature}

Furhmann. G, (1999) stated that the orphanages need immediate attention, improvement in the educational quality, living standards, facilitating training of care givers, staff working in orphanage and providing mental health services into the institution, are needed.

Munchel. J, (2000) analyzed the problems related to the staffing in the institutional settings of limited training, and lack of appropriate supervision for the care givers in orphanage.

Margoob. P, (2006) conducted a study on the adolescent living in orphanages in Kashmir. The result showed that the most common problem faced by the orphans were loss of home, poor recreational facilities, overcrowding, high dropout rate, lack of health care and problems with immunization, child labour and drug abuse among adolescents.

\section{Statement of The Problem}

A research critique on the lived-in experiences of adolescent at selected orphanages in Thiruvallur district. 


\section{Objectives}

1. Elicit the lived-in experiences of adolescent in selected orphanages.

2. Explore the problem revealed by the adolescents.

\section{RESEARCH DESIGN}

\section{Methodology}

Qualitative research design and phenomenological approach was selected for the study.

SETTING OF THE STUDY

A study was conducted in Maranatha Ophanage situated at Srinivasapuram in Ayyapanthangal and Baraniputhur, Chennai.

\section{SAMPLING TECHNIQUE}

The convenient sampling technique was used.

\section{SAMPLE AND SAMPLE SIZE}

The study sample comprised of adolescent who were residing at Maranatha Orphanages in Ayyapanthangal and Baraniputhur. The size of the sample was 15 adolescents. .

\section{POPULATION}

The study population includes male and female adolescent who were staying in the selected orphanages at Thiruvallur district

\section{DATA COLLECTION}

Informed consent was obtained to audio tape interview. Each adolescent was questioned by the investigator an in depth, the interview as conducted on one - to - one basis.

\section{DATA ANALYSIS}

The collected date was analyzed using Colaizzis 7 step methodological interpretation approach.

\section{DESCRIPTION OF THE TOOL}

The tool consists of

Section - A : Socio - Demographic data of the adolescent

Section - B : Interview with open - ended question

\section{Results \& Findings}

The distribution of demographic variables of the adolescents such as age, sex, education and number of living parents. The data indicated that three (20\%) were between the age group of $12-13$ years, and in the age group of $15-16$ years whereas two (13\%) were between the age group of $16-17$ years and seven (47\%) belonged to the age group of $18-19$ years.

Fig:1. Percentage distribution of age of the adolescent in Orphanage homes

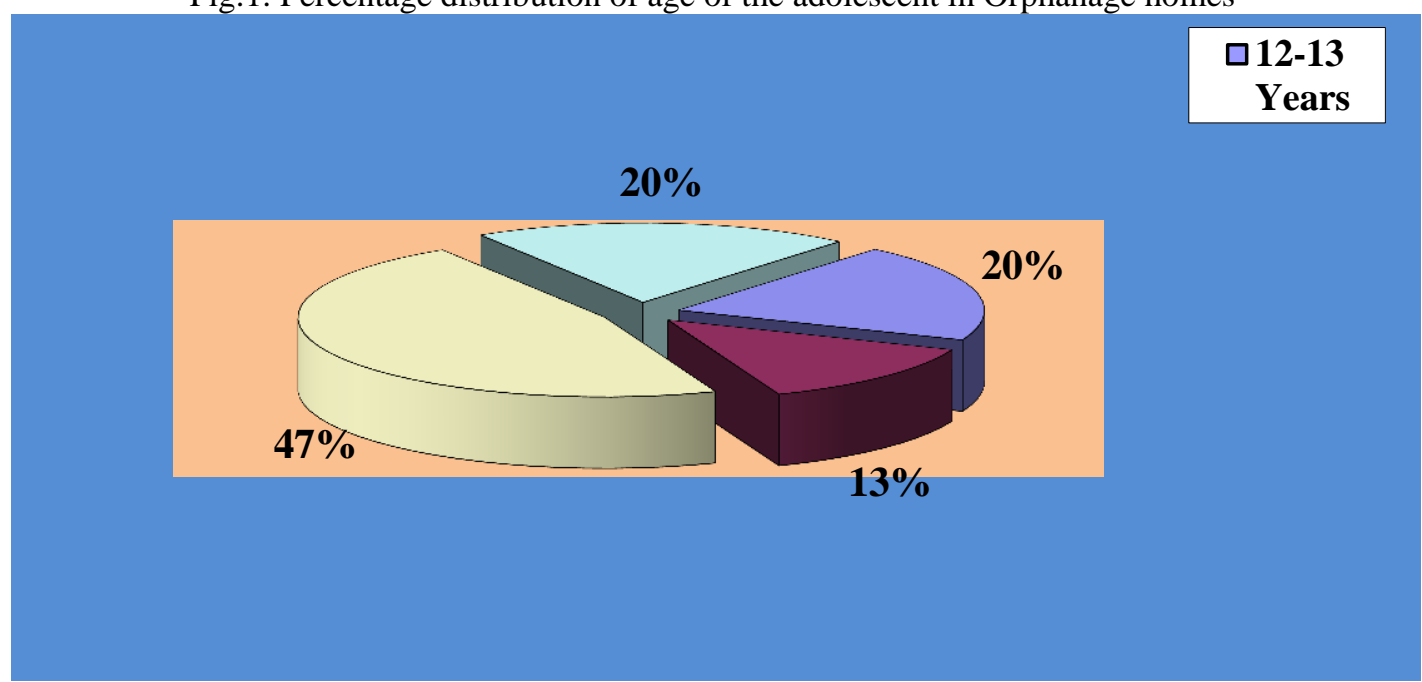

Fig:2. Percentage distribution of living parents of the adolescent in Orphanage homes 


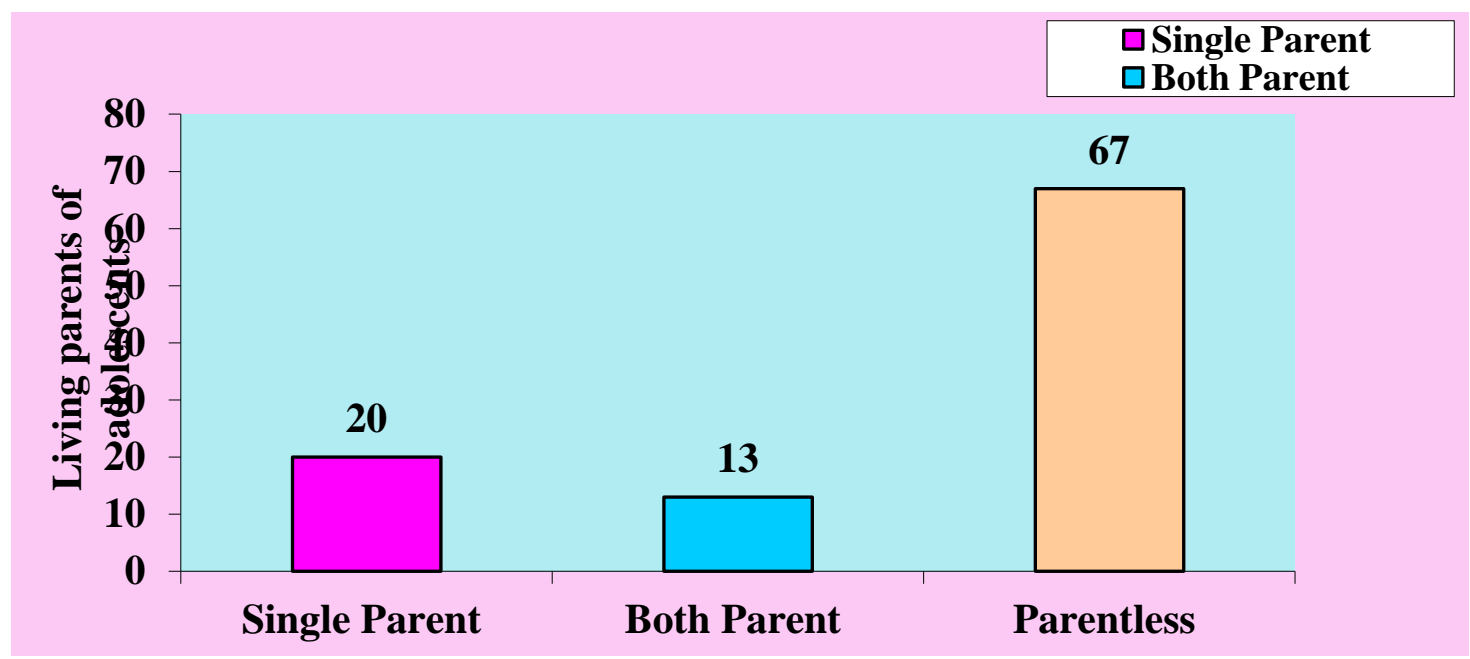

In this study most of the most of the adolescents ten $(67 \%)$ had no parent and three $(20 \%)$ had single parent two $(13 \%)$ had both parents.

adolescents ten (67\%) were male and five $(33 \%)$ were female. With regard to educational status $33 \%$ of the adolescents had education upto the secondary level and ten (67\%) had high school education.

under the following dimension:

1.Physical dimension, 2.Psychological dimension, 3. Emotional dimension, 4.Social dimension, 5.Educational dimension, 6.Spiritual dimension, 7.Vocational dimension.

With regard to food six $(40 \%)$ have received adequate food, four $(27 \%)$ adolescents expressed the inadequacy of food and five (33\%) adolescents expressed that the food was tasty. With regard to the environment two (13\%) adolescents expressed that the food was safe to eat and five (33\%) reported cleanliness and eight $(53 \%)$ of them expressed the poor maintenance of the surrounding.

With regard to the medical help $10(67 \%)$ adolescents reported that they received adequate medical help and five $(33 \%)$ adolescents reported inadequate medical help and $10(67 \%)$ reported that they occasionally fell sick, and five (33\%) would get frequent sickness. With regard to personal hygiene majority $11(73 \%)$ of the adolescents were reported that latrine facility is very poor and four $(27 \%)$ were good.

Regarding other discomfort which was experienced by the adolescents were inadequate ventilation, and inadequate latrine facilities and seven (47\%) expressed inadequately of ventilation, and eight (53\%) had the complaints of inadequate latrine facility.

The findings have highlighted adolescents's feelings, food habits, environmental problem, medical help, sickness, personal hygiene, other discomforts like inadequate latrine facilities, inadequate support from the family and society, emotional reactions like depression, extra-curricular activities, and spiritual aspect like belief in God.

The study showed that most of the adolescents were felt inadequate facilities. The consumption of food is also not adequate for their growth and development. The orphanages should provide adequate attention to each individual in order to have good health.

\section{Recommendations for Future Study}

1. A detailed study can be done for a longer period

2. A descriptive study can be done to assess the needs of orphanage homes.

3. A comparative study can be conducted between orphanage adolescents and other adolescents.

4. A study can be conducted to explore the experience among working members in orphanage home.

\section{References}

[1]. Anes. T (2000). Consequences of an institutionalized adolescents :Indian journal of public health 40 (4) 126-129.

[2]. Assumeberi T.M (2009). Nursing care of children (2 ${ }^{\text {nd }}$ ed.) Philadelphia:W.B Sounders company 221-225.

[3]. Batchelor, (2000). Adaption to childhood parental loss.

[4]. Journal of Neuro sciences, 53(4) 141-146.

[5]. Cohen N.J (2008) Prospective study of their growth and development

[6]. Journal of child psychiatry 49 (4) 458-468.

[7]. Cauduce (2006) Growing responsibilities in the absence of adequate support in orphanages. American journal public health 96 (8) 1429-1435.

[8]. Damribgsach.M (1987) Sulphur for scabies outbuall in orphanages.' 
[9]. Indian journal of paediatrics 19 (5) 448-453.

[10]. Erol. T (2007) Predicts of disruptive behaviour, development delays among institutionalized adolescents, journal of adolescent psychiartry 43 (10) 123-126.

[11]. Eisenberg "Experiences of young adolescents. American journal of medical association 13 (10) 234-236

[12]. Furhmann.G (1999) "Quality of life in orphanages." Journal of adolescent health 17 (4) 51-54.

[13]. Heji.Z (2007) "Quality of life is Orphan.” Journal of adolescent health 42 (4) 410-417. 